\title{
Synergism in Pharmacokinetics of Retagliptin and Metformin Observed during Clinical Trials of their Combination Therapy
}

\author{
Xiaolan Yong ${ }^{1}$, Tingting $\mathrm{Hu}^{1}$, Shiyin Feng ${ }^{1}$, Xiaolin $\mathrm{Du}^{1}$, Huiqing Shi ${ }^{1}$ and Wang \\ Feng $^{2 *}$ \\ ${ }^{1}$ Department of Clinical Pharmacy, The General Hospital of Chendu Military Area Command, ${ }^{2}$ Jiangsu Hengrui Medicine Co \\ Ltd, No. 145 Renming East Road, Lianyunggang City, Jiangsu Province, China
}

*For correspondence: Email: wangfeng8799@163.com; Tel: +86-518-5465745

\begin{abstract}
Purpose: To investigate the safety and potential pharmacokinetic (PK) interaction between retagliptin, a selective inhibitor of dipeptidyl peptidase-4, and metformin in healthy subjects.

Methods: In open-label, randomized, three-period, three-treatment crossover studies, 15 subjects received $100 \mathrm{mg}$ retagliptin, $1500 \mathrm{mg}$ metformin or the combination. The area under the curve from the time of dosing to infinity $\left(A \cup C_{i n f}\right)$ and the maximum observed plasma concentration $\left(C_{\max }\right)$ of each drug were measured.

Results: The combination of retagliptin and metformin did not result in clinically significant alterations in the pharmacokinetics of SP2086 or metformin. The $A U C_{\text {inf }}$ and $C_{\max }$ of retagliptin co-administered with metformin were 16.49 and $25.88 \%$ higher than for retagliptin alone, respectively, while the AUC inf of metformin co-administered with retagliptin was $22.06 \%$ higher than for metformin alone. The $90 \%$ confidence interval of both glucose-lowering drugs' $A \cup C_{\text {inf }}$ and $C_{\max }$ of the geometric mean ratios of SP2086 + metformin fell within the pre-specified interval of $80-125 \%$. No laboratory adverse conditions occurred during the study. Retagliptin appeared generally safe and well-tolerated when administered alone or in combination with metformin.

Conclusion: The results may be an indication that no dose adjustments are likely to be required when retagliptin is given in combination with metformin.
\end{abstract}

Keywords: Retagliptin, Metformin, Pharmacokinetic interaction, Synergism, Type 2 diabetes

Tropical Journal of Pharmaceutical Research is indexed by Science Citation Index (SciSearch), Scopus, International Pharmaceutical Abstract, Chemical Abstracts, Embase, Index Copernicus, EBSCO, African Index Medicus, JournalSeek, Journal Citation Reports/Science Edition, Directory of Open Access Journals (DOAJ), African Journal Online, Bioline International, Open-J-Gate and Pharmacy Abstracts

\section{INTRODUCTION}

Diabetes is a serious public health problem [1-3]. Yang et al has shown that in China, agestandardized prevalence of total diabetes (which include both previously diagnosed diabetes and previously undiagnosed diabetes) and prediabetes was $9.7 \%(10.6 \%$ among men and $8.8 \%$ among women) and $15.5 \%(16.1 \%$ among men and $14.9 \%$ among women), respectively, accounting for 92.4 million adults with diabetes (50.2 million men and 42.2 million women) and 148.2 million adults with prediabetes (76.1 million men and 72.1 million women) [4].

Dipeptidyl peptidase-4 (DPP-4) inhibitors are a relatively new class of drugs for the management of type 2 diabetes [5]. Inhibitors stimulate insulin secretion in a glucose-dependent manner, DPP- 
4 inhibitors present lower risks on hypoglycemia and may not lead to weight gain, also protect pancreatic beta cells. The up-regulation of gastric inhibitory polypeptide and pituitary adenylate cyclase activating polypeptide by DPP-4 inhibitor also result in blood glucose reduction [6,7]. Clinical data indicate that treatment with DPP-4 inhibitors, in combination with other hypoglycemic drugs result in significantly improved glycemic control compared with DPP-4 inhibitor or metformin alone in patients with type 2 diabetes mellitus (T2DM) $[8,9]$.

Retagliptin is a novel DPP-4 inhibitor. Its chemical structure was shown in the Figure 1. Retagliptin has entered into clinical trial phase II in USA under approval by FDA. Our previous clinical studies of retagliptin in healthy volunteers showed a dose-dependent manner in DPP-4 inhibition present a good correlation between DPP-4 inhibition ratio and plasma concentration of retagliptin acid. The objective of the present study was to establish a method to evaluate the safety and pharmacokinetic interaction of synergism of retagliptin combined with metformin in healthy subjects, and to support a clinical protocol of retagliptin combined with metformin.<smiles>CN(C)C(=O)N1C[C@H]2C[C@H](NCC(=O)N3CCC[C@H]3C#N)C[C@H]2C1</smiles>

Fig 1: Structure of retagliptin

\section{METHODS}

\section{Subjects}

The experiment was designed for single center, randomized, opened and three period crossover. The study was carried out in the national clinical drug trial institution of the General Hospital of Chengdu Military Region. The study was approved and registered by the hospital's Ethics Committee in July in 2011 (approval no. CDJ-1107-03). All subjects signed written informed consent form and all aspects of the work were undertaken according to the provisions of the Declaration of Helsinki.

Main inclusion criteria include that participants should be healthy male and female; female should not be pregnant using acceptable method contraception; and subjects aged 18 - 45 years, with a body mass index of $19-24$ were eligible for inclusion. Routine inspection of their medical history, vital signs, safety laboratory tests and electrocardiograms (ECGs) were conducted to determine eligibility for the studies.

The main exclusion criteria include history of allergies or hypersensitivity to the study drugs or their excipients; abuse of drugs or alcohol within 6 months prior to enrollment; use of prescription medications or herbal preparations within 4 weeks prior to enrollment; and use of over-thecounter medication or vitamins within 2 weeks prior to enrollment. Volunteers with evidence of organ dysfunction or any clinically significant deviations from normal in physical examinations, vital signs, electrocardiogram (ECG), or clinical laboratory determinations which may affect drug pharmacokinetics or compliance were also excluded.

\section{Study design}

The study was an open-label, randomized, 3period, 3-treatment $(A, B, C)$, crossover study in healthy subjects. The dosage of retagliptin used in this study was determined by previous trials of single and multiple-dose administration of retagliptin alone. a total of 15 eligible subjects were randomized to 1 of 3 possible treatment sequences $(A B C, B C A, C A B)$ and to receive the following 3 treatment: treatment $A$, retagliptin (100 mg q.d.); treatment $B$, metformin (1500 mg q.d.); treatment $C$, retagliptin (100 $\mathrm{mg}$ q.d.) + metformin (1500 mg q.d.). A 5-day washout period was employed between 5-day treatments periods, after which subjects were crossed over to receive the next treatment specified in their treatment sequence. Blood samples were collected at $2,3,4,5$ day following administration. To confirm steady-state concentration following co-administration, blood samples prior to administration on 2nd, 3rd and 4 th day were analyzed. Figure 2 shows the study design.

Subjects were admitted to a clinical unit one day prior to each study phase with fasting overnight for at least $8 \mathrm{~h}$. Then they received medicine with plain water (retagliptin $100 \mathrm{mg}$ or metformin 1500 $\mathrm{mg}$ or retagliptin $100 \mathrm{mg}+$ metfromin $1500 \mathrm{mg}$ ) after taking baseline examination in the next morning. Subjects were administered medicine before meal every day. Standard meals were served during each treatment periods. Drugs were administered after a $4-\mathrm{h}$ fast and subjects should leave clinical unit until all the plasma sample collection were finished in the 5 days of each treatment phase. 


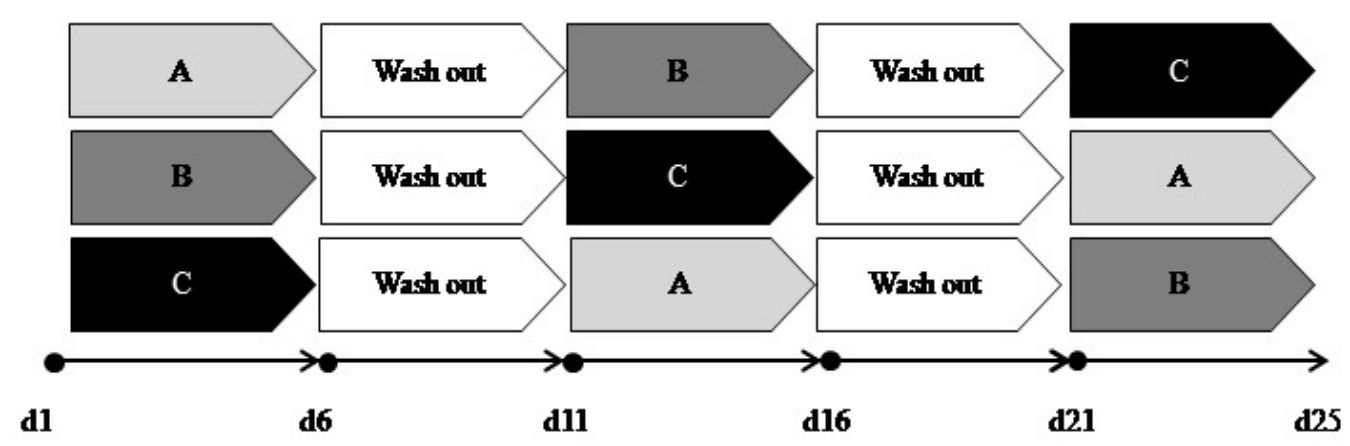

A: SP2086 100mg QD; B: Met 1500mg QD; C- SP2086 100mg QD + Met 1500mg QD.

Fig 2: Study design

\section{Safety assessment}

Safety assessment was based on the characteristics, frequency and severity of adverse events; signs and symptoms of hypoglycemia; physical examination and vital signs; routine safety laboratory tests; urinalysis; hematology; biochemistry and a 12-lead ECG.

The subjects underwent safety examinations before the first dosing, $4 \mathrm{~h}$ after fifth dosing in each phase, and after the last blood collection respectively. If abnormal signs were detected in the third phase before the end of the trials, following up visit is necessary until the patients return to normal condition. During the whole clinical trials the subjects should keep bland diet, avoid strenuous exercises and long period of bed rest. They were forbiddance of juice, tea, and coffee, alcohol which contains caffeine or alcohol. Cigarettes or anything that can affect the pharmacokinetics or safety evaluation were forbidden.

\section{Pharmacokinetic analysis and bioanalysis}

Blood samples for determination of drug concentration and pharmacokinetics were collected at specific time points, depending on the characteristics of each drug.

Plasma concentrations of retagliptin, retagliptin acid (a main metabolite of retagliptin), metformin were determined by separated, validated liquid chromatography-tandem mass spectrometry methods $[10,11]$. The linearity ranges of quantitative detection were 2-200 $\mathrm{ng} / \mathrm{mL}$ for retagliptin; 5 - $1000 \mathrm{ng} / \mathrm{mL}$ for retagliptin acid; 50 - $2000 \mathrm{ng} / \mathrm{mL}$ for metformin. The lower limit of quantitation was $2 \mathrm{ng} / \mathrm{mL}$ for retagliptin, $5 \mathrm{ng} / \mathrm{mL}$ for retagliptin acid and $50 \mathrm{ng} / \mathrm{mL}$ for metformin. The difference between variability for the quality controls of retagliptin was $<8.4$ and $<7.8 \%$, respectively. The difference between variability for the quality controls of retagliptin acid was <
10.8 and $<9.8 \%$, respectively. The difference between variability for the quality controls of metformin was $<3.8$ and $<5.2 \%$, respectively.

\section{Data analysis}

Descriptive statistics including mean, standard deviation, relative standard deviation (RSD), minimum and maximum (range), median and \% CV for continuous variables; and also number, frequency and percentage were conducted. Pharmacokinetic parameters were calculated by non-compartmental methods using WinNonlin software version 6.1 (Pharsight Corp, Mountain View, CA, USA) for plasma.

Pharmacokinetics interactions were assessed by bioequivalency assay. Absence of statistically significant interaction between retagliptin and metformin was confirmed if the $90 \%$ confidence interval $(\mathrm{Cl})$ of both glucose-lowering drugs' $A \cup C_{\text {inf }}$ and $C_{\text {max }}$ of the geometric mean ratios (GMRs) of retagliptin + metformin versus retagliptin alone, fell within the pre-specified interval of $80-125 \%$.

\section{RESULTS}

\section{Pharmacokinetics}

Table 1 showed the descriptive statistics of the pharmacokinetic parameters for retagliptin with or without metformin. Table 2 shows the GMRs and $90 \% \mathrm{Cl}$ of $\mathrm{AUC}_{\text {inf }}$ and $\mathrm{C}_{\max }$ for retagliptin with or without metformin.

As can be seen from Tables 1 and 2, when retagliptin was co-administered with metformin, the $A \cup C_{\text {inf }}$ and $C_{\max }$ of retagliptin were 16.49 and $25.88 \%$ higher than retagliptin alone respectively, and the GMRs and $90 \% \mathrm{Cl}$ for the ratios of $A U C_{\text {inf }}$ and $C_{\max }$ were beyond the upper limit of the interval (80 - $125 \%)$. 
When retagliptin was co-administered with metformin, the $\mathrm{C}_{\max }$ of retagliptin acid increased, and the GMRs and $90 \% \mathrm{Cl}$ for the ratios of $A \cup C_{\text {inf }}$ and $C_{\max }$ fell within the predefined interval (80- $125 \%)$.

When retagliptin was co-administered with metformin, the $\mathrm{AUC}_{\text {inf }}$ of metformin increased $21.77 \%$, and the GMRs and $90 \% \mathrm{Cl}$ for the ratios of $A \cup C_{\text {inf }}$ and $C_{\max }$ fell within the predefined interval (80\% - $125 \%)$. The time profile of the drugs in plasma concentration is displayed in Figure 3.

\section{Safety and tolerability}

During the clinical trials, all subjects were well monitored by researchers.

There were no serious adverse events in the whole trials. The adverse events mainly were gastro-intestinal tract response including nausea, anorexia, sickness and diarrhea. Central nervous system symptoms including dizziness and sleepiness appeared in few subjects. The $A E$ incidence rate of metformin treatment alone was much higher than retagliptin treatment alone. The $\mathrm{AE}$ incidence rate and type of combination treatment was similar with retagliptin or metformin alone. One female subject from the metformin alone group took place moderate diarrhea. The symptoms continued 5 days until the drug withdrawal. The rest of the adverse events were all mild situations. The subjects alleviate by themselves without treatment. All treatments in the trials were well tolerated. The most frequently reported AEs were summarized in Table 3.

No laboratory adverse conditions, including hypoglycemia, or treatment-related clinically significant deviations in physical examinations and ECG parameters occurred during the study.

Table 1: Pharmacokinetic parameters for retagliptin with or without metformin

\begin{tabular}{|c|c|c|c|c|c|c|c|c|}
\hline \multirow{2}{*}{ Drug } & \multirow{2}{*}{ Parameter } & \multirow{2}{*}{ Unit } & \multicolumn{4}{|c|}{ Retagliptin } & \multicolumn{2}{|c|}{ Retagliptin+ metformin } \\
\hline & & & Mean & $S D$ & RSD (\%) & Mean & $S D$ & $R S D(\%)$ \\
\hline \multirow{5}{*}{ Retagliptin } & $t_{1 / 2 z}$ & $\mathrm{~h}$ & 8.3 & 2.3 & 28.0 & 7.8 & 1.4 & 19.0 \\
\hline & $\mathrm{T}_{\max }$ & $\mathrm{h}$ & 1.0 & 0.5 & 50.0 & 1.0 & 0.7 & 70.5 \\
\hline & $\mathrm{C}_{\max }$ & $\mu \mathrm{g} / \mathrm{ml}$ & 64.9 & 35.0 & 54.0 & 81.7 & 40.0 & 48.9 \\
\hline & $A \cup C_{\text {las }}$ & $\mathrm{h}^{*} \mu \mathrm{g} / \mathrm{ml}$ & 295.47 & 68.1 & 23.0 & 344.2 & 73.0 & 21.2 \\
\hline & $A \cup C{ }_{\text {inf }}$ & $\mathrm{h}^{*} \mu \mathrm{g} / \mathrm{ml}$ & 336.84 & 72.0 & 21.4 & 386.55 & 72.9 & 18.8 \\
\hline \multirow{5}{*}{$\begin{array}{l}\text { Retagliptin } \\
\text { acid }\end{array}$} & $t_{1 / 2 z}$ & $\mathrm{~h}$ & 6.1 & 1.9 & 32.0 & 6.1 & 1.6 & 26.8 \\
\hline & $\mathrm{T}_{\max }$ & $\mathrm{h}$ & 1.3 & 0.4 & 36.6 & 1.4 & 0.5 & 39.2 \\
\hline & $\mathrm{C}_{\max }$ & $\mu \mathrm{g} / \mathrm{ml}$ & 1002.98 & 397.31 & 39.6 & 1091.30 & 379.57 & 34.7 \\
\hline & $\mathrm{AUC}_{\text {las }}$ & $\mathrm{h}^{*} \mu \mathrm{g} / \mathrm{ml}$ & 3263.50 & 623.22 & 19.1 & 3469.05 & 726.15 & 20.9 \\
\hline & $A \cup C$ inf & $\mathrm{h}^{*} \mu \mathrm{g} / \mathrm{ml}$ & 3374.98 & 630.62 & 18.6 & 3583.96 & 739.66 & 20.6 \\
\hline \multirow{5}{*}{ Metformin } & $t_{1 / 2 z}$ & $\mathrm{~h}$ & 6.8 & 3.5 & 50.9 & 6.7 & 2.4 & 36.6 \\
\hline & $\mathrm{T}_{\max }$ & $\mathrm{h}$ & 3.3 & 0.8 & 26.7 & 4.0 & 1.1 & 28.6 \\
\hline & $\mathrm{C}_{\max }$ & $\mu \mathrm{g} / \mathrm{ml}$ & 1318.11 & 282.10 & 21.4 & 1226.16 & 358.95 & 29.2 \\
\hline & $A \cup C_{\text {las }}$ & $h^{*} \mu \mathrm{g} / \mathrm{ml}$ & 9591.99 & 2315.55 & 24.1 & 11680.45 & 3993.10 & 34.1 \\
\hline & $A \cup C$ inf & $\mathrm{h}^{*} \mu \mathrm{g} / \mathrm{ml}$ & 10477.14 & 2266.71 & 21.6 & 12788.83 & 4464.85 & 34.9 \\
\hline
\end{tabular}

Table 2: GMRs and $90 \% \mathrm{Cl}$ of $\mathrm{AUC}_{\text {inf }}$ and $\mathrm{C}_{\max }$ for retagliptin with or without metformin

\begin{tabular}{llcc}
\hline Drug & Parameter & Combination/alone & $\mathbf{9 0} \%$ confidence Interval \\
\hline \multirow{2}{*}{ Retagliptin } & $\mathrm{C}_{\max }$ & 122.5 & $90.59 \%-165.69 \%$ \\
\multirow{2}{*}{ Retagliptin acid } & $\mathrm{AUC}$ las & 119.0 & $110.71 \%-128.06 \%$ \\
\multirow{2}{*}{ Metformin } & $\mathrm{C}_{\max }$ & 112.7 & $91.89 \%-138.27 \%$ \\
& $\mathrm{AUC}$ & 107.9 & $102.98 \%-113.19 \%$ \\
& $\mathrm{C}_{\max }$ & 92.4 & $77.51 \%-110.34 \%$ \\
& $\mathrm{AUC}$ & 119.9 & $98.049 \%-146.65 \%$ \\
\hline
\end{tabular}

Table 3: Most common adverse events

\begin{tabular}{lcccccc}
\hline Event/reaction & Medicine group & Positive & Negative & Total & Incidence rate (\%) & $P$-value \\
\hline \multirow{2}{*}{ Adverse } & $\mathrm{A}$ & 3 & 12 & 15 & 20.00 & \\
event & $\mathrm{B}$ & 10 & 5 & 15 & 66.67 & 0.0026 \\
& $\mathrm{C}$ & 12 & 3 & 15 & 80.00 & \\
\hline \multirow{2}{*}{ Adverse reaction } & $\mathrm{A}$ & 2 & 13 & 15 & 13.33 & 0.0007 \\
& $\mathrm{~B}$ & 10 & 5 & 15 & 66.67 & 80.00 \\
\hline
\end{tabular}



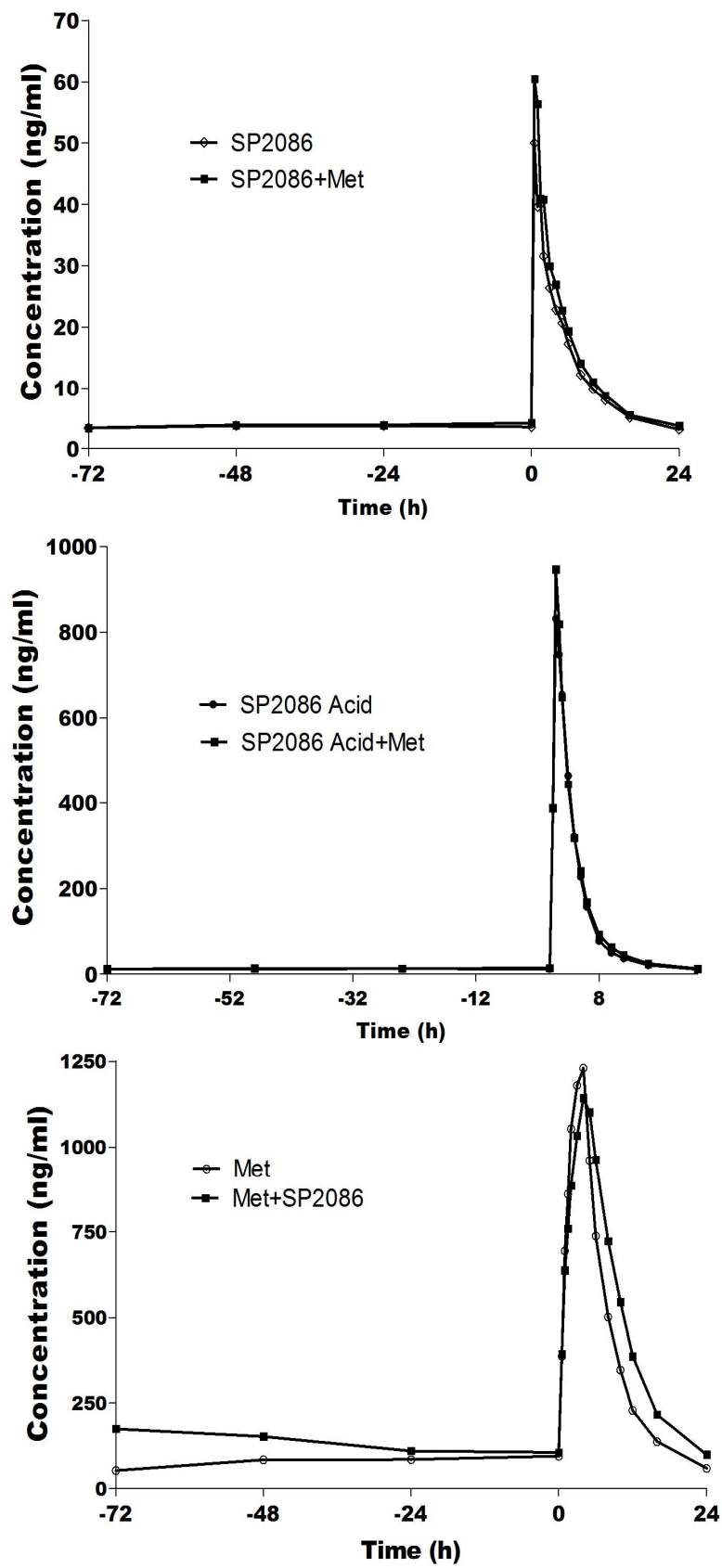

Fig 3: Drug concentration-time of retagliptin, retagliptin acid, metformin following co-administration

\section{DISCUSSION}

Retagliptin has similar chemical structure with vildagliptin (retagliptin), a new DPP-4 inhibitor $[12,13]$. Our pre-clinical studies have demonstrated that retagliptin has similar mechanism to vildagliptin when compared with sitagliptin $[14,15]$. Retagliptin has more effective than sitagliptin in vitro inhibition activity in several diabetes animal models. This will need to be further proved eventually in human patients with diabetes mellitus.
In an attempt to clarify the safety and potential pharmacokinetic interaction between retagliptin, a selective inhibitor of DPP-4, and metformin, we studied their PK interaction in healthy subjects. With this approach it was possible to prove that the combination increased the system exposure of both metformin and retagliptin. Compared with using retagliptin alone, the $\mathrm{C}_{\max }$ increased by $25.88 \%$ in retagliptin combined with metformin hydrochloride sustained-release tablets; the AUC increased by $16.49 \%$. The $90 \%$ confidence interval of AUC ratio of retagliptin acid combination with metformin/retagliptin acid alone was $80-125 \%$, the combination use of drug increased $\mathrm{C}_{\max }$ slightly compared with using drug alone, So dose adjustment is needed when retagliptin combining used with metformin in actual situation, and should be adjusted according to related clinical curative effect analysis and judgment.

Our results showed that the combination increased the system exposure of both metformin and retagliptin, which may be related to the kidney excretion style of the both drugs. It was reported that metformin itself was able to inhibit the activity of DPP-4 [16].

\section{CONCLUSION}

The combination of retagliptin and metformin leads not only to significantly higher $\mathrm{C}_{\max }$ and $A U C_{i n f}$ of retagliptin but also higher $A U C_{\text {inf }}$ of metformin. However, there is no pharmacokinetic interaction between metformin and sitagliptin [17]. The dosage of metformin between $1000 \mathrm{mg}$ and $2500 \mathrm{mg}$ produces similar incidence of gastrointestinal side effects with no obvious dose - effect relationship. No dose-adjustments are likely to be required when retagliptin is given in combination with metformin.

\section{REFERENCES}

1. Shikata K, Ninomiya T, Kiyohara Y. Diabetes mellitus and cancer risk: review of the epidemiological evidence. Cancer Sci 2013; 104: 9-14.

2. Targher G, Byrne CD. Clinical Review: Nonalcoholic fatty liver disease: a novel cardiometabolic risk factor for type 2 diabetes and its complications. J Clin Endocrinol Metab 2013; 98: 483-495.

3. Tricco AC, Ashoor HM, Soobiah C, Hemmelgarn B, Moher D, Hutton B, Yu CH, Majumdar SR, Straus SE. Safety, effectiveness, and cost of long-acting versus intermediate-acting insulin for type 1 diabetes: protocol for a systematic review and network metaanalysis. Syst Rev 2013; 2: 73. 
4. Yang SH, Dou KF, Song WJ. Prevalence of diabetes among men and women in China. N Engl J Med2010; 362: 2425-2426.

5. Neumiller JJ, Wood L, Campbell RK. Dipeptidyl peptidase-4 inhibitors for the treatment of type 2 diabetes mellitus. Pharmacotherapy 2010; 30: 463484.

6. Duez H, Cariou B, Staels B. DPP-4 inhibitors in the treatment of type 2 diabetes. Biochem Pharmacol 2012; 83: 823-832.

7. Sutton JM, Clark DE, Dunsdon SJ, Fenton G, Fillmore $A$, Harris NV, Higgs C, Hurley CA, Krintel SL, MacKenzie RE et al. Novel heterocyclic DPP-4 inhibitors for the treatment of type 2 diabetes. Bioorg Med Chem Lett 2012; 22: 1464-1468.

8. Williams-Herman $D, X u L$, Teng R, Golm GT, Johnson J, Davies MJ, Kaufman KD, Goldstein BJ. Effect of initial combination therapy with sitagliptin and metformin on beta-cell function in patients with type 2 diabetes. Diabetes Obes Metab 2012; 14: 67-76.

9. Olansky L, Reasner C, Seck TL, Williams-Herman DE, Chen $M$, Terranella L, Mehta A, Kaufman $K D$, Goldstein BJ. A treatment strategy implementing combination therapy with sitagliptin and metformin results in superior glycaemic control versus metformin monotherapy due to a low rate of addition of antihyperglycaemic agents. Diabetes Obes Metab 2011; 13: 841-849.

10. Wang Y, Tang Y, Gu J, Fawcett JP, Bai X. Rapid and sensitive liquid chromatography-tandem mass spectrometric method for the quantitation of metformin in human plasma. J Chromatogr B Analyt Technol Biomed Life Sci 2004; 808: 215-219.
11. Mistri HN, Jangid AG, Shrivastav PS. Liquid chromatography tandem mass spectrometry method for simultaneous determination of antidiabetic drugs metformin and glyburide in human plasma. J Pharm Biomed Anal 2007; 45: 97-106.

12. Henness S, Keam SJ. Vildagliptin. Drugs 2006; 66: 19892001.

13. Hoste J, Daci E, Mathieu C. Effectiveness and tolerability of second-line therapy with vildagliptin versus other oral agents in type 2 diabetes (EDGE): post-hoc subanalysis of the Belgian data. Acta Clin Belg 2014; 69: 171-176.

14. Mistry GC, Bergman AJ, Luo WL, Cilissen C, Haazen W, Davies MJ, Gottesdiener KM, Wagner JA, Herman GA. Multiple-dose administration of sitagliptin, a dipeptidyl peptidase-4 inhibitor, does not alter the single-dose pharmacokinetics of rosiglitazone in healthy subjects. J Clin Pharmacol 2007; 47: 159164.

15. Mohan $V$, Yang $W$, Son $H Y, X u L$, Noble L, Langdon RB, Amatruda JM, Stein PP, Kaufman KD. Efficacy and safety of sitagliptin in the treatment of patients with type 2 diabetes in China, India, and Korea. Diabetes Res Clin Pract 2009; 83: 106-116.

16. Lindsay JR, Duffy NA, McKillop AM, Ardill J, O'Harte FP, Flatt $P R$, Bell PM. Inhibition of dipeptidyl peptidase IV activity by oral metformin in Type 2 diabetes. Diabet Med 2005; 22: 654-657.

17. Herman GA, Bergman A, Yi B, Kipnes M, Sitagliptin Study G. Tolerability and pharmacokinetics of metformin and the dipeptidyl peptidase-4 inhibitor sitagliptin when co-administered in patients with type 2 diabetes. Curr Med Res Opin 2006; 22: 1939-1947. 